\title{
Spatial and seasonal variations of organochlorine compounds in air on an urban-rural transect across Tianjin, China
}

\author{
Xiaoyan Zheng ${ }^{\mathrm{a}, \mathrm{b}}$, Dazhou Chen ${ }^{\mathrm{c}}$, Xiande Liu ${ }^{\mathrm{b}}$, Qunfang Zhou ${ }^{\mathrm{a}}$, Yue Liu ${ }^{\mathrm{d}}$, Wen Yang ${ }^{\mathrm{b}}$, Guibin Jiang ${ }^{\mathrm{a}, *}$ \\ ${ }^{a}$ State Key Laboratory of Environmental Chemistry and Ecotoxicology, Research Center for Eco-Environmental Sciences, Chinese Academy of Sciences, Beijing 100085, China \\ ${ }^{\mathrm{b}}$ Chinese Research Academy of Environmental Sciences, Beijing 100012, China \\ ${ }^{\mathrm{c}}$ Nation Research Center of Certified Reference Materials, Beijing 100013, China \\ ${ }^{\mathrm{d}}$ Environmental Monitoring Center of Municipal Tianjin, Tianjin 300191, China
}

\section{A R T I C L E I N F O}

\section{Article history:}

Received 13 May 2009

Received in revised form 7 October 2009

Accepted 10 October 2009

Available online 8 November 2009

\section{Keywords:}

Passive air sampler

OCPs and PCBs

Spatial and seasonal variations

Tianjin

\begin{abstract}
A B S T R A C T
The spatial and seasonal variations of atmospheric organochlorine compounds (OCs) concentrations was investigated at six sites on an urban-rural transect in Tianjin, China from July 2006 to June 2008 using XAD-based passive air samplers. The samplers were deployed for six time periods. Hexachlorocyclohexanes (HCHs) air concentrations were highest at Tanggu and Tuanbowa and decreased dramatically further away from these two sites. The maximum proportion of $\beta-\mathrm{HCH}$ compared to $\Sigma \mathrm{HCHs}(12.1-32.2 \%)$ was found in Hangu, suggesting its persistence. The $\alpha / \gamma-\mathrm{HCH}$ ratio was between 1.26 and 5.79 which signified the combined influence of technical $\mathrm{HCHs}$ and lindane. Dichlorodiphenyltrichloroethane related compounds (DDTs) were higher at Hangu compared with other sites which was attributed to its continuing production there. Low $p, p^{\prime}$-DDE $/ p, p^{\prime}$-DDT in Hangu and Tanggu were found, reflecting the fresh input of DDTs while the relatively high $o, p^{\prime}$-DDT $/ p, p^{\prime}$-DDT ratios indicated the agricultural application of dicofol. Polychlorinated biphenyls distribution elucidated that the urban area could be their emission source. Hexachlorobenzene, with the highest concentrations in Tanggu, showed the smallest industrial/urbanrural gradient ( 4-9 times) than those of other chemicals ( 17-49 for $\Sigma$ HCHs, $\sim 10-77$ for $\Sigma$ DDTs), but comparable with PCBs (PCB28 and PCB52) ( 3-10). Seasonal variations of OCPs were featured by higher concentration in spring and summer and lower in winter. This was likely associated with (i) their temperature-driven re-volatilization and (ii) application of dicofol in late spring and summer and DDTcontaining antifouling paints for fishing ships in summer. However seasonality of PCBs concentrations was site-specific on the Tianjin scale.
\end{abstract}

(c) 2009 Elsevier Ltd. All rights reserved.

\section{Introduction}

China is a key organochlorine pesticides (OCPs) producer worldwide. Approximate 4.9 million tons of hexachlorocyclohexanes (HCHs) and 0.4 million tons of dichlorodiphenyltrichloroethane related compounds (DDTs) were produced from 1950s to 1983, accounting for $33 \%$ and $20 \%$ of the total world production respectively (Fu et al., 2003). High OCPs levels in various environmental media in China have been reported (Fu et al., 2003; Wang et al., 2008b; Liu et al., 2009). However, 10000 tons of polychlorinated biphenyls (PCBs) were produced from 1965 to the early 1980s, consisting of $1 \%$ of global production. PCBs concentrations in the environment were lower when compared with other countries. Ren et al. (2007) recently found that PCBs in the Chinese background/rural soil were approximately one-tenth of the global background soil.

\footnotetext{
* Corresponding author. Tel.: +86 10 62849334; fax: +86 1062849179 .

E-mail address: gbjiang@rcees.ac.cn (G. Jiang).
}

Tianjin was one of the most rapid developing regions in China during the past three decades and also used to be a major area of OCPs manufacture in China. There were two large chemical factories, namely Tianjin Chemical Factory and Tianjin Dagu Chemical Factory. The former, located at Hangu, was the largest HCHs producer in China, ceased production of technical HCHs in 1983 and is still producing DDTs; the latter at Tanggu produced technical HCHs from 1953 to 2000, lindane from 1986 to 2000 and hexachlorobenzene (HCB) from 1958 to 2004 (Cao et al., 2004; Tao et al., 2005, 2007). Furthermore, a great deal of HCHs and DDTs were applied agriculturally from 1953 to 1993 (Tao et al., 2005). A few of studies on OCPs in various environment compartments of Tianjin have been conducted recently which showed that OCPs concentrations in soil, water and sediment in Tianjin were high (Tao et al., 2005; Lü et al., 2007; Tao et al., 2007; Wang et al., 2008b). High DDT concentrations in human tissues (breast milk, blood and fat) have been detected in Tianjin (Wang et al., 2008b) because of their potential for bioaccumulation in the human body through daily exposure. Wu et al. (2005) also found high particle-phase contents 
of OCPs in Tianjin. In a recent survey on atmospheric OCPs of 37 Chinese cities Tianjin was one of cities with the most significant OCPs pollution (Liu et al., 2009). Additionally, Jaward et al. (2005) found that HCB concentration in Tianjin was highest recorded in Asian air. Therefore under strong influence of the Asian monsoon Tianjin could be a major source of OCPs for the Asian-Pacific region. The highest $\mathrm{HCH}$ concentrations in air were observed near Tianjin along the North Pacific Ocean and adjacent Arctic region (Ding et al., 2007).

Due to their lower octanol/air partition coefficients (Koa) these kinds of organochlorine compounds (OCs) are predominately in the atmospheric gas phase (Li et al., 2007; Yang et al., 2008). Passive air samplers (PAS) are a useful semi-quantitative tool to monitor gaseous concentrations of semivolatiles compounds (SVOCs) and have been used widely on a regional and global scale to depict their spatial and temporal variation (Shen et al., 2004; Jaward et al., 2005; Liu et al., 2007; Pozo et al., 2008; Zhang et al., 2008; Liu et al., 2009). In this study gas-phase concentrations of OCPs and PCBs were measured by deploying XAD-2 resin PAS (Wania et al., 2003) at six sites that form an urban-rural transect from July 2006 to June 2008 in Tianjin. To our knowledge, there has been no previous multisite and long term investigation for the OCs of atmospheric gas phase in Tianjin region. OCPs air concentrations and its spatial and seasonal variations are essential for better understanding of the potential role of Tianjin as a source of OCPs on regional and global scales.

\section{Materials and methods}

\subsection{Sampling collection}

Tianjin $\left(\mathrm{E} 116^{\circ} 42^{\prime}-118^{\circ} 04^{\prime}, \mathrm{N} 38^{\circ} 33^{\prime}-40^{\circ} 15^{\prime}\right)$, located in North China Plain and on the west of Bohai Sea, covers an areas of $11919 \mathrm{~km}^{2}$ and has a population over 9.5 million. It is a highly urbanized and industrialized city in China. Six sampling sites were chosen to form an urban-rural transect stretching $130 \mathrm{~km}$ from south to north and $68 \mathrm{~km}$ from east to west (Fig. 1). Tanggu and Hangu, near the Bohai Sea coastal area, are described as industrial/urban. Shizhan in downtown Tianjin is selected to be representative of an urban, high-density residential site. Tuanbowa is characterized as a suburban, medium-density residential site. The last two north sites (Baodi and Yuqiao), far away from downtown Tianjin, were situated in a rural area with small communities of inhabitants.

Passive air samplers were deployed for six periods from July 2006 to June 2008. For operational reasons, the first batch of samplers was deployed over an 8-month period while the other samples were deployed in five subsequent 3-month periods. The last four periods of OCs observations were used in the following interpretation of seasonal variations. The detailed information about PAS locations and periods are listed in Table S1. Duplicate PAS were deployed at each site. Field blanks were produced by briefly installing and removing the resin-filled stainless mesh cylinder into the sampler housing for each sampling period and ten field blank samples in all were collected.

The XAD-2 resin based PAS has been described in detail previously (Wania et al., 2003). Briefly the PAS consists of a resin-filled stainless steel mesh cylinder housed in a galvanized steel cartridge with an open bottom. The PAS is mounted at a height of $1.5 \mathrm{~m}$ above the ground or on the roof of the building. The uptake of contaminants is controlled by molecular diffusion with a constant sampling rate. Mesh cylinders were filled with XAD-2 resin (Supelco, Supepak-2, pre-cleaned Amberlite XAD-2 resin, 20/60 mesh, USA) cautiously, then stored in the airtight aluminum tubes having a Teflon-lined lid before field sampling. After collection resin-filled mesh cylinders were stored in the same tubes and kept at $-18{ }^{\circ} \mathrm{C}$ until analysis. These tubes were rinsed using solvent before use. Polyethylene gloves were used during field operations at sites to avoid potential contamination.

\subsection{Extraction and quantification}

The XAD-2 resin from the PAS was transferred to pre-cleaned thimbles and Soxhlet-extracted with dichloromethane (pesticide grade, Tedia, USA) for $24 \mathrm{~h}$. Prior to the extraction, surrogates 2,4,5,6-tetrachloro-m-xylene (TMX) and PCB209 (from J\&K Company) were added to each sample for assessing method recoveries. The extracts were concentrated and solvent exchanged to iso-octane and further reduced to a final volume of $1 \mathrm{~mL}$ under a gentle stream of pure nitrogen. A known quantity of carbon-13 labeled $\gamma$ $\mathrm{HCH}, \mathrm{HCB}, p, p^{\prime}$-DDE, $p, p^{\prime}$-DDT, PCB28 and PCB52 were added as internal standards. The XAD-2 resins were handled and extracted in a dedicated clean room of the Pilot Laboratory of the UNEP/ GEF POPs Analysis Project.

OCPs and PCBs (PCB28 and PCB52) were analyzed with a Finnigan MAT 900 XL GC-HRMS in selected ion mode (SIM) equipped with a VT-1 capillary column ( $30 \mathrm{~m}$ long, $0.25 \mathrm{~mm}$ i.d., $0.25 \mu \mathrm{m}$ stationary phase). The GC temperature programs were $70^{\circ} \mathrm{C}$ for $1 \mathrm{~min}, 20^{\circ} \mathrm{C} \mathrm{min}^{-1}-150^{\circ} \mathrm{C}, 2^{\circ} \mathrm{C} \mathrm{min}^{-1}-250^{\circ} \mathrm{C}$, held for $20 \mathrm{~min}$. The injector temperature was $210^{\circ} \mathrm{C}$, ion source temperature was $220^{\circ} \mathrm{C}$ and interface temperature was $250^{\circ} \mathrm{C}$. Helium was as carrier gas with a constant flow rate of $1.2 \mathrm{~mL} \mathrm{~min}^{-1}$. The other parameter conditions were as follows: filament, $0.55 \mathrm{ma}, 42 \mathrm{eV}$; electron amplifier, $1.75 \mathrm{kV}$; mass resolution, 10000 . One $\mu \mathrm{L}$ extract was injected in splitless mode and quantified using an internal standard method.

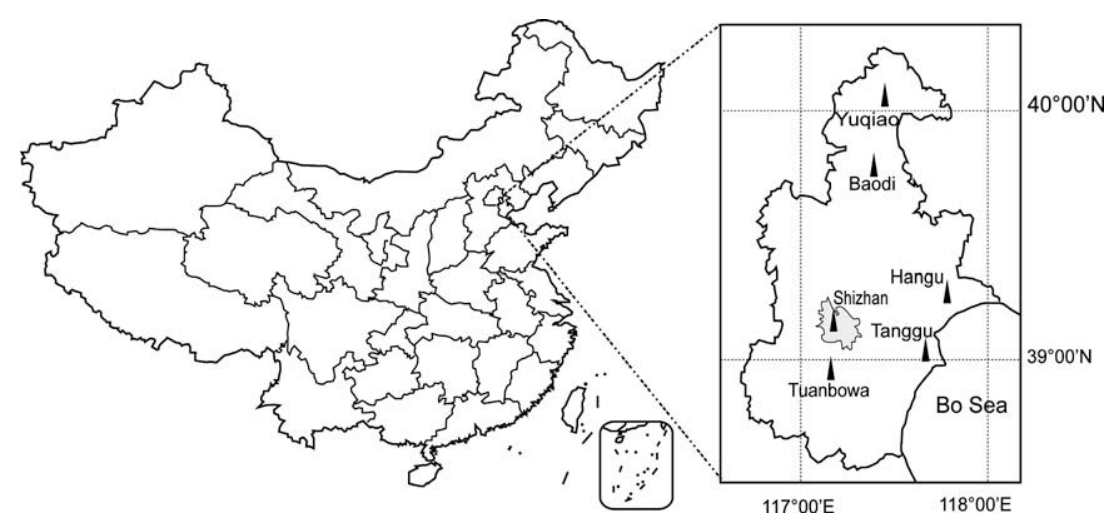

Fig. 1. Study area (Tianjin) and the distribution of sampling locations. 
Ten field blanks and five procedure blanks (solvent with thimbles the same as those used to fill with resin) were analyzed together with the exposed samples. The results showed that minor HCB were detected in field blanks and no interferences were measured in the procedure blank. Our data were thus corrected for the corresponding field blanks. The recoveries of TMX and PCB209 were $90 \pm 13.4 \%$ and $86 \pm 10.8 \%$, respectively. Data shown in this paper were not corrected by the recovery of surrogates. A calibration standard was measured to monitor GC-HRMS performance after 10 injections. The inlet degradation of DDT was $<15 \%$ as daily checked. The method detection limit (MDL) was listed in Table S2.

\section{Results and discussion}

The uptake of OCs by the PAS controlled by molecular diffusion is comparable for different compounds at the same location as discussed in previous studies (Wania et al., 2003; Gouin et al., 2008). Throughout the year a sampling rate $R, 2.0 \mathrm{~m}^{-3} \mathrm{~d}^{-1}$ PAS $^{-1}$ was chosen based on the latest field evaluation study (Gouin et al., 2008). The estimated concentrations in this study appeared to be comparable with the air concentrations reported by previous studies in Tianjin (Jaward et al., 2005; Liu et al., 2009; see Section 3.6), and seasonal variations of OCPs agreed also with previous study of Liu et al. (2009). Therefore, we believe $R, 2.0 \mathrm{~m}^{-3} \mathrm{~d}^{-1} \mathrm{PAS}^{-1}$ as an estimate was reasonable and acceptable. Time-averaged volumetric air concentrations were derived from dividing the mean amount of chemical sequestered in the duplicate XAD-2 sampler (ng PAS ${ }^{-1}$ ) by the product of the PAS sampling rate and the corresponding deployment period days. The reproducibility of duplicates was better than $24 \%$ for all compounds measured. Table 1 summarizes the mean annual air concentrations of OCPs and PCBs of 2 years, namely July 2006-June 2007 and June 2007-June 2008.

\section{Table 1}

Mean annual air concentration $\left(\mathrm{pg} \mathrm{m}^{-3}\right.$ ) of organochlorine compounds derived from PAS at urban-rural transect in Tianjin of July 2006-June 2007 and June 2007-June 2008 .

\begin{tabular}{|c|c|c|c|c|c|c|}
\hline & Tanggu & Hangu & Shizhan & Tuanbowa & Baodi & Yuqiao \\
\hline \multicolumn{7}{|c|}{ July, 2006-June, 2007} \\
\hline$\alpha-\mathrm{HCH}$ & 4497 & 474 & 345 & 493 & 195 & 93 \\
\hline$\beta-\mathrm{HCH}$ & 203 & 316 & 33 & 65 & 15 & 2.9 \\
\hline$\gamma-\mathrm{HCH}$ & 2082 & 185 & 223 & 264 & 106 & 62 \\
\hline$\delta-\mathrm{HCH}$ & 345 & 48 & 45 & 99 & 27 & 5.9 \\
\hline$\Sigma \mathrm{HCHs}$ & 7128 & 1023 & 646 & 921 & 344 & 164 \\
\hline $\mathrm{HCB}$ & 1674 & 864 & 619 & 699 & 366 & 195 \\
\hline$p, p^{\prime}-\mathrm{DDE}$ & 46 & 255 & 54 & 63 & 34 & 19 \\
\hline$p, p^{\prime}-\mathrm{DDD}$ & 3.4 & 6.7 & 1.1 & 2.0 & 0.77 & 0.92 \\
\hline$o, p^{\prime}-\mathrm{DDT}$ & 46 & 309 & 30 & 31 & 22 & 11 \\
\hline$p, p^{\prime}-\mathrm{DDT}$ & 49 & 249 & 19 & 20 & 13 & 8.6 \\
\hline$\Sigma$ DDTs & 144 & 819 & 104 & 116 & 70 & 39 \\
\hline PCB28 & 21 & 21 & 45 & 50 & 17 & 7.9 \\
\hline PCB52 & 5.3 & 4.4 & 14 & 12 & 3.7 & 1.8 \\
\hline$\Sigma$ PCBs & 26 & 25 & 59 & 63 & 21 & 9.7 \\
\hline \multicolumn{7}{|c|}{ June, 2007-June, 2008} \\
\hline$\alpha-\mathrm{HCH}$ & 3411 & 532 & 683 & 1022 & 297 & 136 \\
\hline$\beta-\mathrm{HCH}$ & 186 & 288 & 83 & 115 & 21 & 6.1 \\
\hline$\gamma-\mathrm{HCH}$ & 1477 & 162 & 283 & 291 & 110 & 62 \\
\hline$\delta-\mathrm{HCH}$ & 167 & 37 & 62 & 94 & 24 & 3.5 \\
\hline$\Sigma \mathrm{HCHs}$ & 5242 & 1019 & 1111 & 1522 & 452 & 208 \\
\hline $\mathrm{HCB}$ & 1801 & 1234 & 1011 & 1150 & 564 & 386 \\
\hline$p, p^{\prime}-\mathrm{DDE}$ & 73 & 548 & 102 & 96 & 49 & 33 \\
\hline$p, p^{\prime}-\mathrm{DDD}$ & 4.8 & 14.4 & 3.6 & 2.3 & 1.4 & 1.0 \\
\hline$o, p^{\prime}-\mathrm{DDT}$ & 62 & 714 & 70 & 57 & 25 & 14 \\
\hline$p, p^{\prime}-\mathrm{DDT}$ & 74 & 653 & 43 & 31 & 19 & 9.8 \\
\hline$\Sigma D D T s$ & 215 & 1928 & 219 & 186 & 94 & 58 \\
\hline РCB28 & 38 & 38 & 65 & 58 & 24 & 23 \\
\hline PCB52 & 9.8 & 8.5 & 19 & 15 & 6.7 & 6.1 \\
\hline$\Sigma$ PCBs & 48 & 46 & 84 & 73 & 30 & 29 \\
\hline
\end{tabular}

\subsection{Spatial and seasonal variations of $\mathrm{HCHs}$}

HCHs were widely used as two formulations. One was technical $\mathrm{HCH}$ which is a mixture of $\alpha-\mathrm{HCH}(60-70 \%), \beta-\mathrm{HCH}(5-12 \%), \gamma-$ $\mathrm{HCH}(10-12 \%)$ and $\delta$ - $\mathrm{HCH}(6-10 \%)$. The other was lindane, which contains approximately $99 \%$ of $\gamma-\mathrm{HCH}$, the $\mathrm{HCH}$ isomer of highest pesticide activity. In China technical HCHs was banned in 1983 and lindane was used as a substitute for the next 10 years. In 1992 lindane was also restricted officially. Tianjin was one of the most severely HCHs polluted areas in China (Cao et al., 2004). High concentrations of $\mathrm{HCHs}$ were detected in soil, which could revolatilize and contribute to the local air concentration (Wu et al., 2005; Wang et al., 2006a; Tao et al., 2008).

Table 1 shows the mean annual air concentrations of HCHs derived from PAS. $\Sigma \mathrm{HCHs}$ (sum of $\alpha-\mathrm{HCH}, \beta-\mathrm{HCH}, \gamma-\mathrm{HCH}$ and $\delta-\mathrm{HCH}$ ) along the urban-rural transect demonstrated significant spatial variability. Their mean concentrations $\left(\mathrm{pg} \mathrm{m}^{-3}\right)$ were in the range of 164-7128 and 208-5242 for 2 years, respectively. In all sampling periods, the concentrations of $\Sigma \mathrm{HCHs}$ including each $\mathrm{HCH}$ isomer, in Tanggu, were the highest. As mentioned above, the Tianjin Dagu chemical factory was situated at Tanggu District. Although its production of HCHs was shut down at the end of 2000, the residues of HCHs were still significant 6 years later when our study was carried out and thus led to the peak values. Other studies also found that HCHs were more abundant in sediment, water, soil and aerosols at Tanggu (Gong et al., 2004; Wu et al., 2005; Wang et al., 2007b, 2008a; Tao et al., 2008). The second highest values of $\Sigma$ HCHs were found at Tuanbowa in most periods except MarchJune 2007. From 1970 to 1990 agriculture application of great amounts of HCHs had been practiced in Tianjin (Gong et al., 2004; Wang et al., 2006a; Tao et al., 2008). Tuanbowa was one area with high amount of HCHs applied for agriculture in Tianjin during 1970s (Gong et al., 2004). Although the agriculture application of $\mathrm{HCHs}$ was terminated more than a decade ago, the HCHs levels in soils in the area of Tuanbowa are still elevated (Gong et al., 2004; Wang et al., 2006a). It is likely that soil bound HCHs were re-emitted from soil to air, resulting in the enhanced concentration in Tuanbowa. At other sites HCHs were about 1 or 2 orders of magnitude lower, particularly at the rural site of Yuqiao, further away from Tanggu and Tuanbowa (Table 1 and Fig. 2).

Generally $\alpha-\mathrm{HCH}$ and $\gamma-\mathrm{HCH}$ were dominant in Tianjin air. It is interesting to note that the concentration of $\beta-\mathrm{HCH}$ in Hangu air was abnormally high (Table 1 ). Furthermore $\beta-\mathrm{HCH}$ residue proportion of $\mathrm{\Sigma HCHs}(12.1-32.2 \%)$ was the highest in Hangu

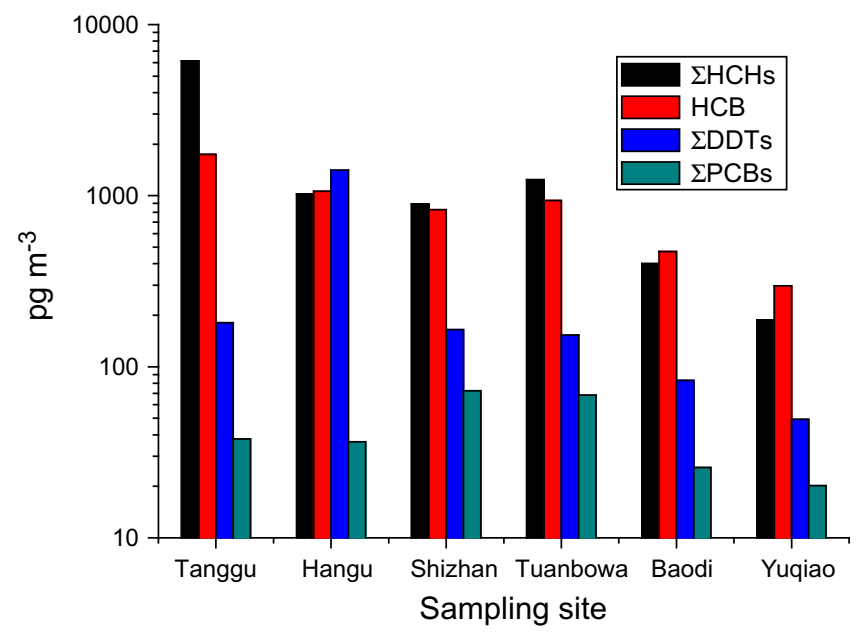

Fig. 2. Spatial variation of the mean OCs concentrations of each site over the entire sampling campaign on the urban-rural transect in Tianjin. 
compared with the other sites (Fig. S1). As discussed before Tianjin Chemical Factory in Hangu was the largest production of technical HCHs more than two decades ago in China. After the ban of technical HCHs in 1983 the other $\mathrm{HCH}$ isomers residue in Hangu air were reduced sharply, while $\beta-\mathrm{HCH}$ was still stable. This is because $\beta$ $\mathrm{HCH}$ has symmetric chemical structure that its chlorines are all in the equatorial positions resulting in its physical and metabolic stability compared to the other isomers (Willett et al., 1998) and tends to stay in the source region after application. By comparison $\alpha-\mathrm{HCH}$ and $\gamma-\mathrm{HCH}$ are inclined to long-range atmospheric transport (Li et al., 2002) due to their higher vapor pressure. Carlson et al. (2004) found that $\beta-\mathrm{HCH}$ concentrations in precipitation and vapor phase for the Great Lakes region showed an increase as a function of time whereas this was not found for $\alpha-\mathrm{HCH}$ and $\gamma-\mathrm{HCH}$. Therefore it was concluded that $\beta-\mathrm{HCH}$ could be the predominant isomer in air with time elapse in source regions. These findings indicated the continuing role of industrial area and historical residue of agriculture application in Tianjin as emission sources of $\mathrm{HCHs}$.

It has been suggested that the value and change of $\alpha / \gamma-\mathrm{HCH}$ ratio in space and time was strongly affected by the usage of technical HCHs (ratio 3.6-15) (Wang et al., 2006b) and lindane (ratio $<0.1$ ) (Willett et al., 1998) as well as their persistence and physicochemical properties. In this work the observed ratio of $\alpha / \gamma-\mathrm{HCH}$ along urban-rural transect in Tianjin was fairly uniform, ranging from 1.26 to 2.15 in July 2006-March 2007, from 1.35 to 3.96 in March-June 2007, from 1.90 to 2.88 in June-September 2007, from 1.81 to 2.87 in September-December 2007, from 2.33 to 5.40 in December-March 2008, from 2.42 to 5.79 in March-June 2008 (Table S3). These values were mostly between the ratio of technical $\mathrm{HCHs}$ and lindane. A survey in 2004 pointed out recent input of $\mathrm{HCHs}$ across Haihe Plain (including Tianjin) is very unlikely (Tao et al., 2008). Thereby the less varied ratio indicated that HCHs in air has similar contributors across Tianjin, most possibly caused by the integrated influence of technical HCHs and lindane. Additionally $\alpha / \gamma-\mathrm{HCH}$ ratio exhibited an increasing trend with time in this study (Fig. S2). Compared with $\gamma-\mathrm{HCH}, \alpha-\mathrm{HCH}$ has lower Koa (Shoeib and Harner, 2002) and lower hydroxyl-reaction degradation (Brubaker Jr. and Hites, 1998) resulting in a longer atmospheric lifetime for $\alpha-\mathrm{HCH}$. Moreover $\gamma-\mathrm{HCH}$ could be converted to $\alpha-\mathrm{HCH}$ by the photoisomerization (Malaiyandi and Shah, 1984), resulting in a higher $\alpha / \gamma-\mathrm{HCH}$. Ding et al. (2007) also found increasing $\alpha / \gamma-\mathrm{HCH}$ ratios with increasing latitude along the North Pacific Ocean and the adjacent arctic regions because of disproportionate chemical reduction and physical fractioning during longrange transport.

Seasonal variations of $\mathrm{HCHs}$ in air were apparent (Fig. 3 and Fig. S3). HCH air concentrations generally increased with the rising of atmosphere temperature and maximum values occurred during summer, and decreased $\sim 6-30$ times with the falling temperature and showed minimum values in winter. However, concentrations of $\alpha-\mathrm{HCH}$ at Tanggu and Tuanbowa in spring were somewhat higher than those in summer. It may be due to their highest $\mathrm{HCH}$ air concentrations observed across Tianjin.

\subsection{Spatial and seasonal variations of $H C B$}

It began in 1958 to produce HCB in China. After 1983, output of HCB was reduced drastically. From 1988 to 2004 (when production was totally stopped) there was only one factory in China, Tianjin Dagu Chemical Factory, yielding 80000 tons of HCB, $98.8 \%$ of which was used as a precursor in the manufacture of sodium pentachlorophenol and pentachlorophenol for schistosome control, and the rest of which was used to make pyrotechnics (The People's Republic of China, 2007).

The mean annual concentrations of HCB in Tianjin are listed in Table 1. For all periods HCB showed an industrial/urban-rural gradient, confirming industrial/urban areas, especially Tanggu as the source in Tianjin (Table 1 and Fig. 2). HCB has multiple sources in the environment. In China HCB is not likely from pesticide application because it was prohibited from direct use as a pesticide (The People's Republic of China, 2007). However HCB as a byproduct of chlorination manufacturing and combustion process as well as reemission of 'old' HCB from soils and water could contribute to ambient levels (Barber et al., 2005). Tanggu and Hangu are major industrial zones in Tianjin where some HCB is generated unintentionally in course of substantial chlor-alkali production. Higher reemission of 'old' HCB from Tanggu surface compartments may be occurring due to past production of HCB (Barber et al., 2005), which resulted in higher concentrations of HCB in Tanggu than those in Hangu. Concentration variations of HCB ( 4-9 times) between sites were relatively small, while other OCPs varied by orders of magnitude, which could be ascribed to its lower Koa tending to be uniformly distributed in the atmosphere (Shoeib and Harner, 2002; Barber et al., 2005).

Seasonal variations of HCB are plotted in Fig. S4. In general, the concentrations peaked in spring and summer with similar levels and decreased with a drop in temperature in fall and winter. This pattern was attributed to the equilibrium of HCB shifting towards the atmosphere at higher temperatures and towards the soil and other surface compartments at lower temperatures.

It was worth noting that HCB in winter at Shizhan were slightly higher than in fall. Shizhan lies in the most populous area of Tianjin and combustion activities related to domestic heating increased greatly in winter, which could lead to the elevated HCB concentrations. Additionally, the profile of HCB seasonal variation in industrial/urban sites, Tanggu and Hangu, was a little different from the others. HCB in fall was slightly decreased while a sharp decrease was observed in winter (Fig. S4). Although seasonal variation of HCB mainly depended on temperature-controlled revolatilization, it was also likely associated with the contribution of some chlor-alkali manufacture process. During 2007 chlor-alkali
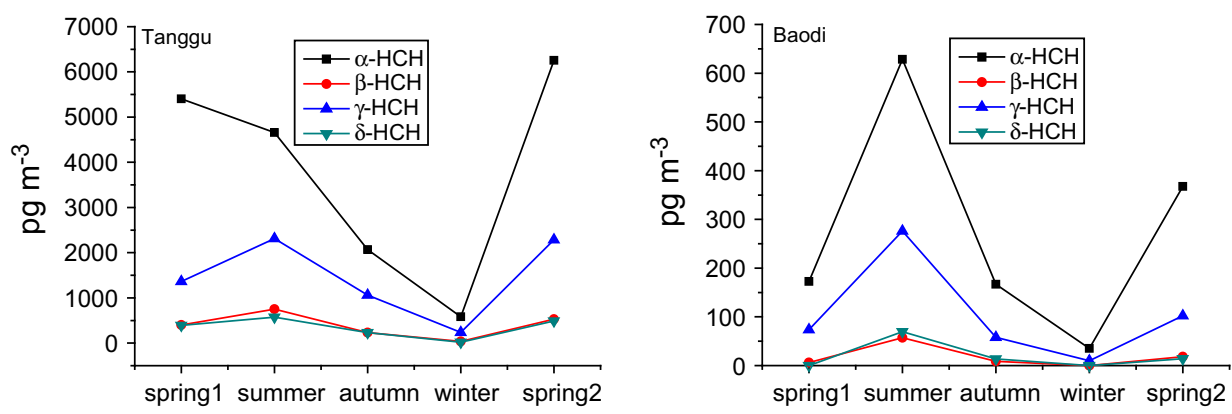

Fig. 3. Seasonal variations of HCHs concentrations at Tanggu and Baodi in Tianjin, China (spring 1: March-June 2007; spring 2: March-June 2008). 
production declined except in September and October (http:// www.qrx.cn/newsView.aspx?ID=82706); which could indirectly influence the HCB air concentration in fall (from September to December) in 2007.

\subsection{Spatial and seasonal variations of DDTs}

In 1983 the Chinese government deregistered DDTs as a pesticide and restricted its production (The People's Republic of China, 2007). After that time, several thousand tons of technical DDTs were produced per year. From 1950s to 2004 73\% DDTs produced in China was used as a precursor for dicofol production and the $\sim 4 \%$ as an effective additive for antifouling paints. The remaining ( $23 \%$ ) was exported for disease vector control (The People's Republic of China, 2007).

The mean annual air concentrations of $\Sigma$ DDTs (the sum of $p, p^{\prime}-$ $\left.\mathrm{DDE}+p, p^{\prime}-\mathrm{DDD}+o, p^{\prime}-\mathrm{DDT}+p, p^{\prime}-\mathrm{DDT}\right)$ for 2 years were 39$819 \mathrm{pg} \mathrm{m}^{-3}$ and $58-1928 \mathrm{pg} \mathrm{m}^{-3}$, respectively (Table 1 ). DDTs was another dominant pesticide that had been applied in Tianjin. Since the termination of its use in agriculture, DDTs residues have declined by one order of magnitude in soil, water and sediment (Tao et al., 2007, 2008). However, technical DDTs is still produced in Hangu, which likely increases the DDT load in the local environment. This is supported by the fact that DDT air concentrations were the highest in Hangu, followed by another industrial site (Tanggu), urban and suburban sites (Shizhan and Tuanbowa) and two rural sites (Baodi and Yuqiao) (Table 1 and Fig. 2).

The ratios of $p, p^{\prime}$-DDE $/ p, p^{\prime}$-DDT and $o, p^{\prime}$-DDT $/ p, p^{\prime}$-DDT have been used successfully to distinguish the source of DDTs (Harner et al., 2004; Qiu et al., 2005; Li et al., 2007; Wang et al., 2007a; Yang et al., 2008; Liu et al., 2009). p,p'-DDT was the major component in technical DDTs ( $\geqslant 70.0 \%$ ). Therefore a ratio of $p, p^{\prime}-\mathrm{DDE} / p, p^{\prime}-$ DDT much greater than one indicates aged DDTs, while ratios less than one indicate fresh inputs. $0, p^{\prime}$-DDT $/ p, p^{\prime}$-DDT has been employed as an indicator of dicofol application. Dicofol, a nonsystemic acaricide is still being used extensively in China and consists of considerable $o, p^{\prime}$-DDT impurities that is the predominant species. The ratio of $o, p^{\prime}$-DDT $/ p, p^{\prime}$-DDT in dicofol is about 7 (Qiu et al., 2005). whereas in technical DDTs the ratio of $o, p^{\prime}$-DDT $/ p, p^{\prime}$-DDT is about 0.2 (Harner et al., 2004). Therefore elevated $o, p^{\prime}$-DDT/ $p, p^{\prime}$-DDT in the environment is indicative of the dicofol-type DDT pollution (Qiu et al., 2005).

In this study the lowest $p, p^{\prime}$-DDE $/ p, p^{\prime}$-DDT ratios are shown at Hangu and Tanggu, suggesting fresh inputs of DDTs there (Table S3). In the case of Hangu local DDTs production is the likely cause of this result, while as to Tanggu, the proximity to the fishery center of Tianjin may be playing a role due to the large number of fishing ships at anchor. For coastal areas DDT-containing antifouling paints are used regularly on fishing ships to prevent the adhesion of halobios (e.g. barnacles, mollusks and algae) and may be a potential source of DDTs observed as low $p, p^{\prime}$-DDE $/ p, p^{\prime}$-DDT ratio and elevated DDT levels were observed at Tanggu. Furthermore large amounts of technical DDTs exported through Tianjin Harbor near the Tanggu site could also result in a low observed $p, p^{\prime}-$ DDE/p,p'-DDT ratio (Wang et al., 2009). At the other four sampling sites, $p, p^{\prime}$-DDE $/ p, p^{\prime}$-DDT ratios were all much greater than 1 , suggesting no recent agricultural application of DDTs around Tianjin, which is in accord with the results of previous studies on soil (Wang et al., 2006a; Tao et al., 2008). Higher $0, p^{\prime}$-DDT/p, $p^{\prime}$-DDT ratios in air were observed all over Tianjin (Table S3) which could be explained by the agricultural application of dicofol, although the amount was likely limited (Qiu et al., 2005; Wu et al., 2005).

In the environment different volatilization rate of different DDT compounds can lead to the fractionation of these compounds and thus shift the ratios of DDTs. As discussed in Liu et al. (2009), the contributions of technical DDTs and dicofol-type DDTs to air could be predicted using the subcooled liquid-phase vapor pressures $\left(p_{\mathrm{L}}^{0}\right)$ of $o, p^{\prime}$-DDT and $p, p^{\prime}$-DDT given that only these two types of DDT sources are the dominant emission in the environment. The contributions are calculated as following equation:

$$
\begin{aligned}
R_{\mathrm{air}\left(o, p^{\prime}-\mathrm{DDT} / p, p^{\prime}-\mathrm{DDT}\right)}= & \left(R_{\mathrm{S} 1\left(o, p^{\prime}-\mathrm{DDT} / p, p^{\prime}-\mathrm{DDT}\right)} * x+R_{\mathrm{S} 2\left(o, p^{\prime}-\mathrm{DDT} / p, p^{\prime}-\mathrm{DDT}\right)} * y\right) \\
& * p_{\mathrm{L}\left(o, p^{\prime}-\mathrm{DDT} / p, p^{\prime}-\mathrm{DDT}\right)}^{0}
\end{aligned}
$$

$x+y=1$

where $R_{\mathrm{air}\left(o, p^{\prime}-\mathrm{DDT} / p, p^{\prime}-\mathrm{DDT}\right)}$ is the ratio of $o, p^{\prime}$-DDT/p, $p^{\prime}$-DDT in the air, $R_{\mathrm{S} 1\left(o, p^{\prime}-\mathrm{DDT} / p, p^{\prime}-\mathrm{DDT}\right)}$ and $R_{\mathrm{S} 2\left(o, p^{\prime}-\mathrm{DDT} / p, p^{\prime}-\mathrm{DDT}\right)}$ are the ratios of $o, p^{\prime}$-DDT/ $p, p^{\prime}$-DDT in source 1 , technical DDTs and source 2, dicofol; and $x$ and $y$ are the contribution of the two sources. $p_{\mathrm{L}}^{0}$ of $o, p^{\prime}$-DDT and $p, p^{\prime}$-DDT are selected from the study of Shoeib and Harner (2002). As shown in Table S4, the DDT sources in Tianjin air were composed of $72-93 \%$ of technical DDTs and $7-28 \%$ of dicofol-type DDTs, similar to the source inventory data in Tianjin. Interestingly it was shown that the contribution portion of technical DDTs were always higher in Tanggu than in Hangu, confirming that there was more technical DDT source in Tanggu, namely DDT-containing antifouling paint.

In Tianjin, DDTs in air exhibited seasonal pattern with the maximum values in summer and minimum values in winter (Fig. 4 and Fig. S5). Those highest concentrations in summer were partly related to the volatilization of DDTs residue from surface media during the warmer seasons. Dicofol application in late spring and summer was another reason. Additionally some DDT-containing antifouling paint usage to maintain fish ships may also contribute to the high level of DDTs found in the summer samples during legislative fishing moratorium from 16 June to 1 September (http:// news.sina.com.cn/c/2008-06-16/133114025143s.shtml).

\subsection{Spatial and seasonal variations of two indicative $P C B$ congeners}

In China 9000 tons of PCBs was as trichlorobiphenyl dominating products (namely No. 1 PCB) and 1000 tons as pentachlorobiphenyl
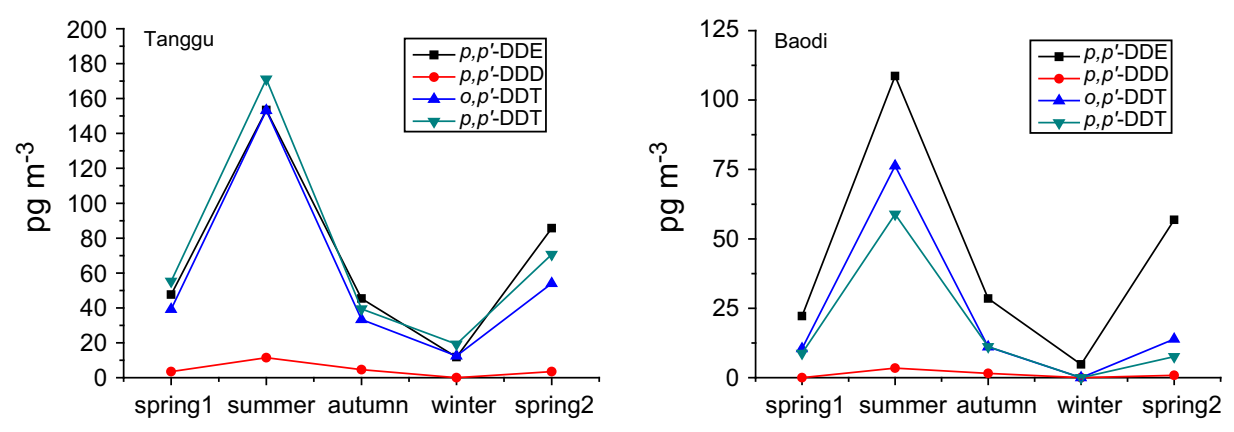

Fig. 4. Seasonal variations of DDTs concentrations at Tanggu and Baodi in Tianjin, China. 
dominating products (namely No. 2 PCB). No. 1 PCB was primarily used as a coolant in electrical equipment and No. 2 PCB as paint additives (The People's Republic of China, 2007; Ren et al., 2007). Assumed that these two technical PCBs were blended according to the ratio of their production amount, that is 9:1, the major homologue composition of mixtures is tri-PCB, followed tetra-PCB (Ren et al., 2007). Although the homologue composition of the global PCB products also mainly consists of tri-PCB followed by tetra-PCB, the compositional ratio of the tri-PCB to tetra-PCB is higher in Chinese products (40.4-31.1\%) than in global products $(25.2-24.7 \%)$ (Ren et al., 2007).

According to other surveys on a national scale, PCBs in air, soil, sediment, water and organisms near Tianjin is at a moderate level of China (Xing et al., 2005; Ren et al., 2007; Zhang et al., 2008). Its emissions to air are possibly due to volatilization from environmental reservoirs and atmospheric transport from other areas. Compared with other organochlorine compounds in Tianjin, PCB concentrations were much lower. Table 1 shows the mean annual values $\left(\mathrm{pg} \mathrm{m}^{-3}\right.$ ) of $\Sigma$ PCBs (sum of tri-PCB, PCB28 and tetra-PCB, PCB52): from 9.7-59 and 29-84 for each of 2 years, with the peak concentrations at the urban site (Shizhan) and the suburban site (Tuanbowa) (Table 1 and Fig. 2). Shizhan is in the densely populated urban area of Tianjin and the majority of electrical equipment containing PCBs in Tianjin were used there three decades ago, which was likely responsible for the observed maximum values. Tuanbowa is not far away of downtown (Fig. 1). This implied that urban area could be possible source of PCBs (Motelay-Massei et al., 2005; Zhang et al., 2008). The relatively low PCB concentrations at other sites were due to increased distance from the urban area. However, PCB28/PCB52 ratios across Tianjin were about $\sim 4$ (Table S3), reflecting the similar source of PCBs in Tianjin. A recent study indicated that similar PCB congener profiles in Chinese air was observed with tri-PCB showing the highest concentration followed by tetra-PCB and agreed well with the profile of Chinese technical PCBs (Zhang et al., 2008). Therefore PCBs in Tianjin air were also likely from those products.

Seasonalities of PCBs were also obvious, but variable from site to site (Fig. S6). The lower concentrations in winter could be attributed to depressed re-volatilization from surface media under cold conditions. It was found that seasonal variations were more evident at Shizhan and Hangu, similar to the pattern of HCHs, HCB and DDTs. And thus the Clausius-Clapeyron equation was used to differentiate local emission from long-range atmospheric transport. This equation is described as

Ln $P=m / T+b$

where $P$ is the SVOCs partial pressure (Pa), $m$ is the slope and $T$ is the average air temperature $(\mathrm{K})$. It was proposed that a steeper slope or high temperature dependence indicates that evaporation from surface close to the sampling location controls the air concentrations of SVOCs, whereas shallow slopes result from advection of air masses from regional background concentrations. The application of Clausius-Clapeyron equation have been well documented in previous studies (Wania et al., 1998; Shen et al., 2004; Yeo et al., 2004; Li et al., 2007)

The PCB concentrations in the six periods were applied to the Eq. (1). It is showed that the high slopes of PCB28 and PCB52 in Shizhan are observed with a level of significance of $p<0.05$, implying the local source, i.e. secondary emission from surface compartments near Shizhan. Interestingly, the slope in Hangu is also higher for PCB28 $(p<0.05)$ and PCB52 $(p<0.10)$ (Table S5), indicating possible influence from chemical industrial process there. The result of $\mathrm{C}-\mathrm{C}$ equation calculations indicated that PCBs seasonalities in Tianjin were greatly influenced by atmospheric transport, particularly for rural sites with low PCBs concentrations. Additionally $\mathrm{C}-\mathrm{C}$ equation was also applied to HCHs, HCB, and DDTs. Slopes with obvious significance level were mostly higher than those of PCBs, reflecting that strong local contribution of OCPs in Tianjin (Table S6).

\subsection{Comparison between two springs}

As seen from Figs. 3 and 4 and Figs. S3-S6, it was found that the OCs values of spring 2008 were basically higher than those of spring 2007, indicating that PAS can provide the information of year to year change of OCs concentrations. The OCs concentrations ratios of two spring (2008/2007) are given in Table S7. The variations of HCB ratios between sampling sites were smallest among these OCs ratios, demonstrating HCB was apt to distribute evenly. For each site the ratios of HCHs, DDTs and PCBs should have respective similarities which indeed showed up.

To evaluate further the similarity of compounds within a group and the possible difference between groups, the correlation coefficients were calculated (Table S8). One can see that compounds of $\mathrm{HCHs}$ and DDTs had high correlation coefficients, in the range of $0.78-0.99$ and $0.64-0.92$, respectively. The highest value 0.99 is with two indicative PCB congeners. On the other hand, compounds from different groups were not necessarily in good correlations, as they were quite different in emission sources, in transport behavior, in physico-chemical properties. In summary XAD-based PAS demonstrates its usefulness as a tool for monitoring POPs in the atmosphere.

\subsection{Comparison with previous studies}

As shown in Table S9, seasonal air concentrations of OCs in Tianjin were compared with previous studies (Jaward et al., 2005; Liu et al., 2009). For Shizhan site, although different PAS approaches were deployed, HCHs and HCB concentrations agreed mostly within a factor of three between this study and Liu et al. (2009); while DDTs concentrations in this study were somewhat lower. As for Tanggu site, DDTs and two indicative PCB congeners were consistent with previous study (Jaward et al., 2005); however, HCB were not matched well with each other, which may be explained by the saturation of PUF-disk PAS for high concentrations at Tanggu site (Jaward et al., 2005). Obviously OCPs air concentrations in Tianjin, especially industrial/urban areas, were generally higher than most of the other Chinese cities (Jaward et al., 2005; Liu et al., 2009). It was shown that passive air samplers could be used as a valuable semi-quantitative tool for long term monitoring of POPs air concentrations in urban areas in China.

\section{Conclusions}

Elevated concentrations of $\mathrm{HCHs}$ and $\mathrm{HCB}$ were found in the atmosphere of Tanggu, Tianjin where these two kinds of chemicals were produced. Higher DDTs concentrations were observed in Hangu, related to continued production of DDTs there. Higher PCB air concentrations in Shizhan and Tuanbowa sites implied the importance of urban source, which may be due to the past usage of PCB-containing electrical equipment. On the whole the air concentrations of OCs in Tianjin were consistent with previous results.

Distinct seasonal variations of OCPs were found in the Tianjin area. HCHs and HCB were observed in higher concentration during summer and spring and relatively lower concentration during winter, mainly attributed to re-emission from surface media. DDTs increased in concentration in summer and dropped in winter because seasonal usage of dicofol and DDT-containing antifouling paints for fishing ships. PCBs had site-specific seasonal variations 
due to variable contribution from local sources and regional atmospheric transport.

OCPs levels in Tianjin area were relatively high, especially for the industrial areas. This means that strengthened measures are needed to deal with the POPs issue in Tianjin area. These data provide temporal values for long term studies in the future and regional baseline values for policy makers to stipulate better implementation strategies on Stockholm Convention.

\section{Acknowledgements}

This work was supported by the National Basic Research Program of China (Grant No. 2009CB421605 and No. 2003CB415003) and the State High Tech Development Plan (863 Program, No. 2006AA06Z424). We thank Dr. Mark D. Loewen from University of Manitoba and two reviewers for their constructive suggestions. We also thank China Meteorology Bureau for meteorological data.

\section{Appendix A. Supplementary material}

Supplementary data associated with this article can be found, in the online version, at doi:10.1016/j.chemosphere.2009.10.017.

\section{References}

Barber, J.L., Sweetman, A.J., van Wijk, D., Jones, K.C., 2005. Hexachlorobenzene in the global environment: emissions, levels, distribution, trends and processes. Sci. Total Environ. 349, 1-44.

Brubaker Jr., W.W., Hites, R.A., 1998. OH reaction kinetics of gas-phase $\alpha$ - and $\gamma$ hexachlorocyclohexane and hexachlorobenzene. Environ. Sci. Technol. 32, 766769.

Cao, H.Y., Tao, S., Xu, F.L., Coveney, R.M., Cao, J., Li, B.G., Liu, W.X., Wang, X.J., Hu, J.Y., Shen, W.R., Qin, B.P., Sun, R., 2004. Multimedia fate model for hexachlorocyclohexane in Tianjin, China. Environ. Sci. Technol. 38, 2126-2132.

Carlson, D.L., Basu, I., Hites, R.A., 2004. Annual variations of pesticide concentrations in great lakes precipitation. Environ. Sci. Technol. 38, 5290-5296.

Ding, X., Wang, X.M., Xie, Z.Q., Xiang, C.H., Mai, B.X., Sun, L.G., Zheng, M., Sheng, G.Y., Fu, J.M., 2007. Atmospheric hexachlorocyclohexanes in the North Pacific Ocean and the adjacent Arctic region: spatial patterns, chiral signatures, and sea-air exchanges. Environ. Sci. Technol. 41, 5204-5209.

Fu, J.M., Mai, B.X., Sheng, G.Y., Zhang, G., Wang, X.M., Peng, P.A., Xiao, X.M., Ran, R., Cheng, F.Z., Peng, X.Z., Wang, Z.S., Tang, U.W., 2003. Persistent organic pollutants in environment of the Pearl River Delta, China: an overview. Chemosphere 52, 1411-1422.

Gong, Z.M., Xu, F.L., Dawson, R., Cao, J., Liu, W.X., Li, B.G., Shen, W.R., Zhang, W.J., Qin, B.P., Sun, R., Tao, S., 2004. Residues of hexachlorocyclohexane isomers and their distribution characteristics in soils in the Tianjin area, China. Arch. Environ. Contam. Toxicol. 46, 432-437.

Gouin, T., Wania, F., Ruepert, C., Castillo, L.E., 2008. Field testing passive air samplers for current use pesticides in a tropical environment. Environ. Sci. Technol. 42, 6625-6630.

Harner, T., Shoeib, M., Diamond, M., Stern, G., Rosenberg, B., 2004. Using passive air samplers to assess urban-rural trends for persistent organic pollutants. 1 . Polychlorinated biphenyls and organochlorine pesticides. Environ. Sci. Technol. 38, 4474-4483.

Jaward, F.M., Zhang, G., Nam, J.J., Sweetman, A.J., Obbard, J.P., Kobara, Y., Jones, K.C., 2005. Passive air sampling of polychlorinated biphenyls, organochlorine compounds, and polybrominated diphenyl ethers across Asia. Environ. Sci. Technol. 39, 8638-8645.

Li, Y.F., Macdonald, R.W., Jantunen, L.M.M., Harner, T., Bidleman, T.F., Strachan, W.M.J., 2002. The transport of $\beta$-hexachlorocyclohexane to the western Arctic Ocean: a contrast to $\alpha$-HCH. Sci. Total Environ. 291, 229-246.

Li, J., Zhang, G., Guo, L.L., Xu, W.H., Li, X.D., Lee, C.S.L., Ding, A.J., Wang, T., 2007. Organochlorine pesticides in the atmosphere of Guangzhou and Hong Kong: regional sources and long-range atmospheric transport. Atmos. Environ. 41, 3889-3903.

Liu, W.J., Chen, D.Z., Liu, X.D., Xie, W.M., Li, B.W., Dai, T.Y., 2007. Application of passive air sampler in monitoring organochlorine pollutants in atmosphere. Res. Environ. Sci. 20, 9-14 (in Chinese).

Liu, X., Zhang, G., Li, J., Yu, L.L., Xu, Y., Li, X.D., Kobara, Y., Jones, K.C., 2009. Seasonal patterns and current sources of DDTs, chlordanes, hexachlorobenzene, and endosulfan in the atmosphere of 37 Chinese cities. Environ. Sci. Technol. 43, 1316-1321.

Lü, J.X., Wang, Y.W., Zhang, Q.H., Gao, E.L., Jiang, G.B., 2007. Contamination trends of polybrominated diphenyl ethers, organochlorine pesticides and heavy metals in sediments from Dagu Drainage River estuary, Tianjin. Chin. Sci. Bull. 52, 1320 1326.

Malaiyandi, M., Shah, S.M., 1984. Evidence of photoisomerization of hexachlorocyclohexane isomers in the ecosphere. J. Environ. Sci. Health 19 887-910.

Motelay-Massei, A., Harner, T., Shoeib, M., Diamond, M., Stern, G., Rosenberg, B., 2005. Using passive air samplers to assess urban-rural trends for persistent organic pollutants and polycyclic aromatic hydrocarbons. 2. Seasonal trends for PAHs, PCBs, and organochlorine pesticides. Environ. Sci. Technol. 39, 57635773.

Pozo, K., Harner, T., Lee, S.C., Wania, F., Muir, D.C.G., Jones, K.C., 2008. Seasonally resolved concentrations of persistent organic pollutants in the global atmosphere from the first year of the GAPS Study. Environ. Sci. Technol. 42, 8999-9004

Qiu, X.H., Zhu, T., Yao, B., Hu, J.X., Hu, S.W., 2005. Contribution of dicofol to the current DDT pollution in China. Environ. Sci. Technol. 39, 4385-4390.

Ren, N.Q., Que, M.X., Li, Y.F., Liu, Y., Wan, X.N., Xu, D.D., Sverko, E., Ma, J.M., 2007. Polychlorinated biphenyls in Chinese surface soils. Environ. Sci. Technol. 41 3871-3876.

Shen, L., Wania, F., Lei, Y.D., Teixeira, C., Muir, D.C.G., Bidleman, T.F., 2004 Hexachlorocyclohexanes in the north American atmosphere. Environ. Sci. Technol. 38, 965-975.

Shoeib, M., Harner, T., 2002. Using measured octanol-air partition coefficients to explain environmental partitioning of organochlorine pesticides. Environ. Toxicol. Chem. 21, 984-990.

Tao, S., Xu, F.L., Wang, X.J., Liu, W.X., Gong, Z.M., Fang, J.Y., Zhu, L.Z., Luo, Y.M., 2005. Organochlorine pesticides in agricultural soil and vegetables from Tianjin, China. Environ. Sci. Technol. 39, 2494-2499.

Tao, S., Li, B.G., He, X.C., Liu, W.X., Shi, Z., 2007. Spatial and temporal variations and possible sources of dichlorodiphenyltrichloroethane (DDT) and its metabolites in rivers in Tianjin, China. Chemosphere 68, 10-16.

Tao, S., Liu, W.X., Li, Y., Yang, Y., Zuo, Q., Li, B.G., Cao, J., 2008. Organochlorine pesticides contaminated surface soil as reemission source in the Haihe Plain, China. Environ. Sci. Technol. 42, 8395-8400.

The People's Republic of China, 2007. National Implementation Plan for the Stockholm Convention on Persistent Organic Pollutants. In: Government, C.C. (Ed.).

Wang, X.J., Piao, X.Y., Chen, J., Hu, J.D., Xu, F.L., Tao, S., 2006a. Organochlorine pesticides in soil profiles from Tianjin, China. Chemosphere 64, 1514-1520.

Wang, X.P., Yao, T.D., Cong, Z.Y., Yan, X.L., Kang, S.C., Zhang, Y., 2006b. Gradient distribution of persistent organic contaminants along northern slope of centralHimalayas. China. Sci. Total Environ. 372, 193-202.

Wang, J., Guo, L.L., Li, J., Zhang, G., Lee, C.S.L., Li, X.D., Jones, K.C., Xiang, Y.R., Zhong L.J., 2007a. Passive air sampling of DDT, chlordane and HCB in the Pearl River Delta, South China: implications to regional sources. J. Environ. Monit. 9, 582588.

Wang, T., Zhang, Z.L., Huang, J., Hu, H.Y., Yu, G., Li, F.S., 2007b. Occurrence of dissolve polychlorinated biphenyls and organic chlorinated pesticides in the surface water of Haihe River and Bohai Bay, China. Environ. Sci. 28, 730-735 (in Chinese).

Wang, T., Huang, J., Yu, G., 2008a. Distribution of polychlorinated biphenyls and organochlorine pesticides in sediment of the Haihe River and Bohai Bay. J. Tsinghua Univ. 48, 82-85 (in Chinese).

Wang, Y.R., Zhang, M., Wang, Q., Yang, D., Li, C., Liu, J., Li, J., Li, H., Yang, X., 2008b Exposure of mother-child and postpartum woman-infant pairs to DDT and its metabolites in Tianjin. China. Sci. Total Environ. 396, 34-41.

Wang, G., Lu, Y.L., Wang, T.Y., Zhang, X., Han, J.Y., Luo, W., Shi, Y.J., Li, J., Jiao, W.T., 2009. Factors influencing the spatial distribution of organochlorine pesticides in soils surrounding chemical industrial parks. J. Environ. Qual. 38, 180-187.

Wania, F., Haugen, J.E., Lei, Y.D., Mackay, D., 1998. Temperature dependence of atmospheric concentrations of semivolatile organic compounds. Environ. Sci. Technol. 32, 1013-1021.

Wania, F., Shen, L., Lei, Y.D., Teixeira, C., Muir, D.C.G., 2003. Development and calibration of a resin-based passive sampling system for monitoring persistent organic pollutants in the atmosphere. Environ. Sci. Technol. 37, 1352-1359.

Willett, K.L., Ulrich, E.M., Hites, R.A., 1998. Differential toxicity and environmental fates of hexachlorocyclohexane isomers. Environ. Sci. Technol. 32, 2197-2207.

Wu, S.P., Tao, S., Zhang, Z.H., Lan, T., Zuo, Q., 2005. Distribution of particle-phase hydrocarbons, PAHs and OCPs in Tianjin, China. Atmos. Environ. 39, 7420-7432.

Xing, Y., Lu, Y.L., Dawson, R.W., Shi, Y.J., Zhang, H., Wang, T.Y., Liu, W.B., Ren, H.C., 2005. A spatial temporal assessment of pollution from PCBs in China. Chemosphere 60, 731-739.

Yang, Y.Y., Li, D.L., Mu, D., 2008. Levels, seasonal variations and sources of organochlorine pesticides in ambient air of Guangzhou, China. Atmos. Environ. 42, 677-687.

Yeo, H.G., Choi, M., Sunwoo, Y., 2004. Seasonal variations in atmospheric concentrations of organochlorine pesticides in urban and rural areas of Korea. Atmos. Environ. 38, 4779-4788.

Zhang, Z., Liu, L.Y., Li, Y.F., Wang, D.G., Jia, H.L., Harner, T., Sverko, E., Wan, X.N., Xu, D.D., Ren, N.Q., Ma, J.M., Pozo, K., 2008. Analysis of polychlorinated biphenyls in concurrently sampled Chinese air and surface soil. Environ. Sci. Technol. 42 6514-6518. 